7th International Conference on Innovations in Chemical, Agricultural, Biological and Environmental

Sciences (ICABES-2017)

London (UK) Dec. 4-6, 2017

\title{
Valorisation of Polyethylene and Plastic Bottle Wastes as Pavement Blocks
}

\author{
B. Mohammed ${ }^{1 . *}$ and F. P. Afangide ${ }^{2}$ \\ ${ }^{1}$ Department of Agricultural and Environmental Resources Engineering, Faculty of Engineering, \\ University of Maiduguri, PMB 1069 Maiduguri, Nigeria \\ ${ }^{2}$ Department of Agricultural and Environmental Engineering, Faculty of Technology, \\ University of Ibadan, Ibadan, Nigeria
}

\begin{abstract}
In this research, the possibility of using waste low-dense polyethylene and waste plastic bottles for the production of interlock pavement blocks was investigated. In many parts of the world, interlock pavement block is used widely as modern-day solution to outdoor flooring applications and the blocks have different shapes, sizes and colours suiting the imagination of landscape architects and installation engineers. Using a suitable and conventional mould with a $220 \times 135 \times 50 \mathrm{~mm}^{3}$ shape, interlock block samples were produced using the waste materials. The constituent materials of the produced blocks were waste low-dense polyethylene and waste plastic bottles mixed in varying, respective percentage-weight proportions of; $100 \%+0 \%, 75 \%+25 \%$, $50 \%+50 \%$ and $25 \%+75 \%$. Using the same approach, control conventional concrete interlock block samples were also produced. All the block samples were then tested for unconfined compressive strength (UCS) and water absorption (WA) properties. The test results for both the UCS and WA compared well with those of conventional concrete interlock blocks and the research demonstrates the possibility of value recovery from these waste streams that are currently dumped in open-spaces thereby affecting the environment.
\end{abstract}

Keywords: Pavement blocks, polyethylene, plastic bottle, wastes, valorisation.

\section{Introduction}

Traditional construction materials such as concrete, bricks, hollow blocks, solid blocks, pavement blocks and tiles are normally being produced from the existing natural resources. This has a negative impact on the environment due to continuous exploitation and depletion of natural resources. Additionally, various toxic substances such as high concentration of carbon monoxide and suspended particulate matters are often invariably emitted to the atmosphere during the production process of construction materials. These emissions affect the environment and could affect human health and standard of living. Therefore, the issues related to environmental conservation have gained great importance in our society in recent years (Xue et al., 2009). Hence, major changes regarding the conservation of resources and recycling of wastes are evolving very fast - leading to re-using wastes in sustainable ways (Cyr et al., 2004; Siddique, 2010; Mohammed and Cheeseman, 2011). The utilization of solid wastes in construction materials is one of such innovative efforts as the cost of construction materials is increasing daily because of high demand, scarcity of raw materials and high price of energy especially in developing countries. From the standpoint of energy saving and conservation of natural resources, the use of alternative constituents in construction materials has a global attraction now. For this, the extensive research and development works towards exploring new ingredients are required for producing sustainable and environment friendly construction materials. This study investigates the potential use of plastic solid wastes in the production of construction materials. To safeguard the environment, many efforts are being made for the recycling of different types of solid wastes with a view to utilising them in the production of various construction materials. Plastics are non-biodegradable. Principlal types of plastics found in waste are those used 
as trash bags, grain storage bags, shopping bags, bottles, packaging and containers, light spongy material used in meat, eggs and miscellaneous products trays, hot beverage cups, yogurt containers, straws, margarine tubs and special bags. Most of these plastics are discarded after single use and become garbage. The manufacturing of plastics involve various chemical processes and utilizes variety of chemical compounds and additives including phenols, amines and esters, antioxidants, UV and light stability improvers, antistatic agents and heat stabilizers that impart the finished product specific characteristics for its intended use. The finished product that is the plastic itself is reported to be environmentally quite stable. However, the additives, their chemical reaction and degradation products incorporated into the polymeric material are reported to have the potential to be released into the environment and cause significant health and environmental concerns (Valavanidid et al., 2004; Wang et al., 2004; Klyosov, 2005; ASTM, 2005; Lee and Shin, 1995).

There are many sources of plastic waste and municipalities are one of them. The term municipal solid waste (MSW) describes those waste materials that are collected by the municipality itself or by the authorized organization. The municipal solid wastes come from residential, commercial, institutional and industrial sources MSW consists of waste materials such as newspaper, cans and bottles, food waste, food packaging, clothing, appliances, yard wastes, household hazardous waste, corrugated boxes, office papers and plastics film etc Consumption of plastics has steadily increased over the years due their flexibility, affordability and durability as compared to other materials with similar use. Thousands of tones of plastics are generated annually around the globe. A large fraction of waste plastics still ends up in the landfills and/or is burned unlawfully in the open by the users often in developing countries. Being readily combustible, these plastics when burned under open and uncontrolled fire conditions at low temperatures generate black plumes of smoke and toxic volatilization products, which become incorporated into the ambient environment, resulting in human and environmental exposure.

Terminology for plastics recycling is complex and sometimes confusing because of the wide range of recycling and recovery activities. These include four categories: primary (mechanical reprocessing into a product with equivalent properties), secondary (mechanical reprocessing into products requiring lower properties), tertiary (recovery of chemical constituents) and quaternary (recovery of energy).

One of the great things about recycling is that this process helps to minimize the presence of waste materials in our environment as they do not end up taking up space in a landfill somewhere. Since most people are not interested in having a garbage dump located near them, recycling make it possible to avoid creating newer and larger landfills that would otherwise be necessary to accommodate all the wastes. Recycling of waste is done to achieve many benefits (Agbede and Manasseh, 2008; Folagbade, 1998; Yang et al., 2009).

The main objective of this study is to investigate the potential recycling of waste plastic bottle and polyethylene as construction product and ensure value recovery from this waste stream.

\section{Materials and Method}

\subsection{Materials}

The interlock block samples were produced at different percentage combinations of $100 \%, 75 \%, 50 \%$ and 25\%. The waste plastic bottle and low dense polyethylene wastes were collected within the University of Maiduguri community. A conventional I-shape metallic mould with measurements of $223 \mathrm{~mm}$ length, $35 \mathrm{~mm}$ breath and $53 \mathrm{~cm}$ thickness was fabricated along with a metallic crucible. The waste plastic bottles used in the research were discarded water bottle, plastic Coca-Cola bottle and other soft-drink bottles and malt-drink bottles referred as high dense polyethylene plastic (HDPEP). The low dense polyethylene plastic (LDPEP) used in the research was mainly used and discarded water-sachet. Other equipment used were an open-tong (for holding the crucible from the furnace and for easy pouring of the melted waste into the mould); a skimmer (for stirring or removing impurities from the melted waste); a furnace (for the melting process at $120^{\circ} \mathrm{C}$ to $200^{\circ} \mathrm{C}$ ); a stop-watch (for timing the process); a compressive strength testing machine; and a small quantity of spent-engine oil (used as a lubricant for easy demoulding and to avoid the melted polymer from sticking to the surface of the mould). 
See Figs. 1 and 2.

a)
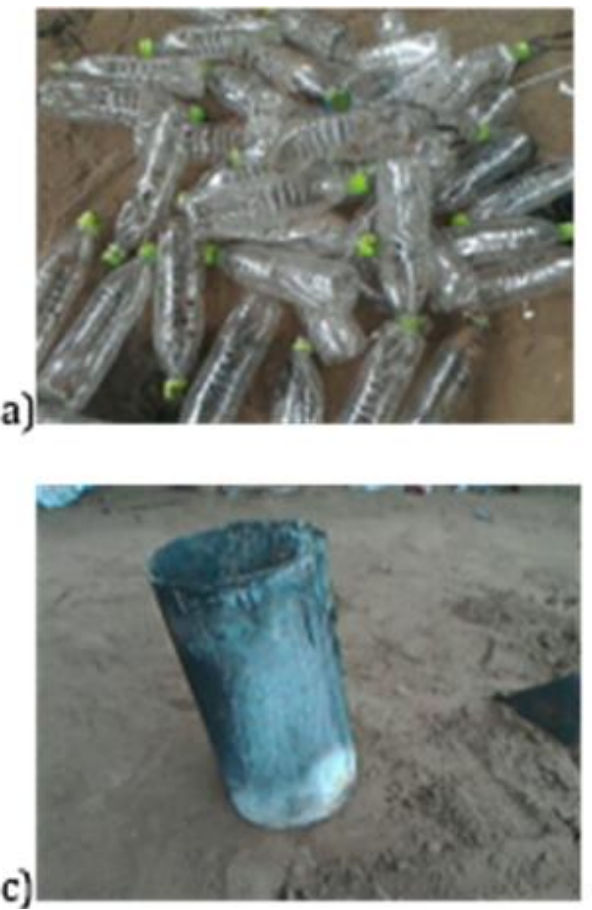

d)
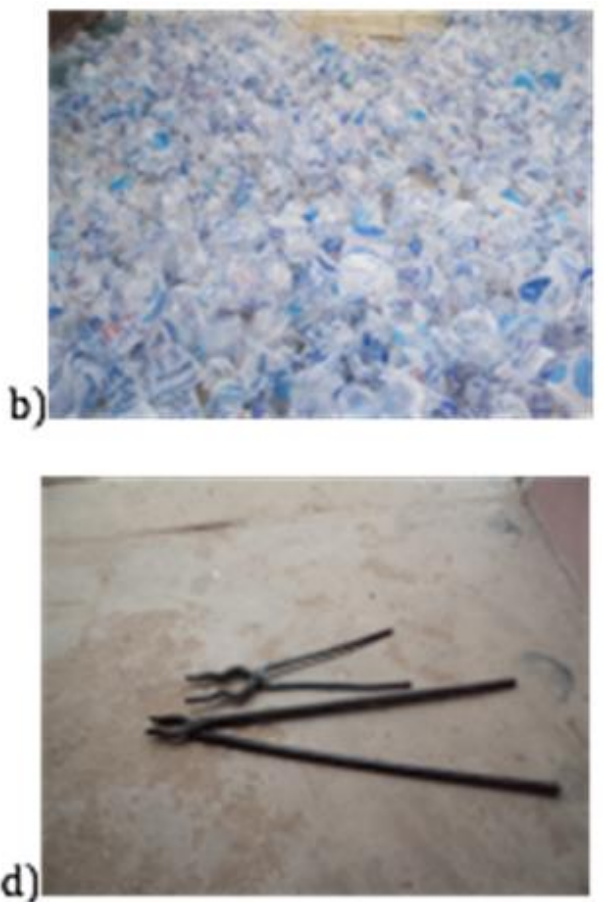

Fig. 1: a) Some of the waste water bottles; b) Used water-sachet; c) Crucible; and d) Open-end metallic tong.
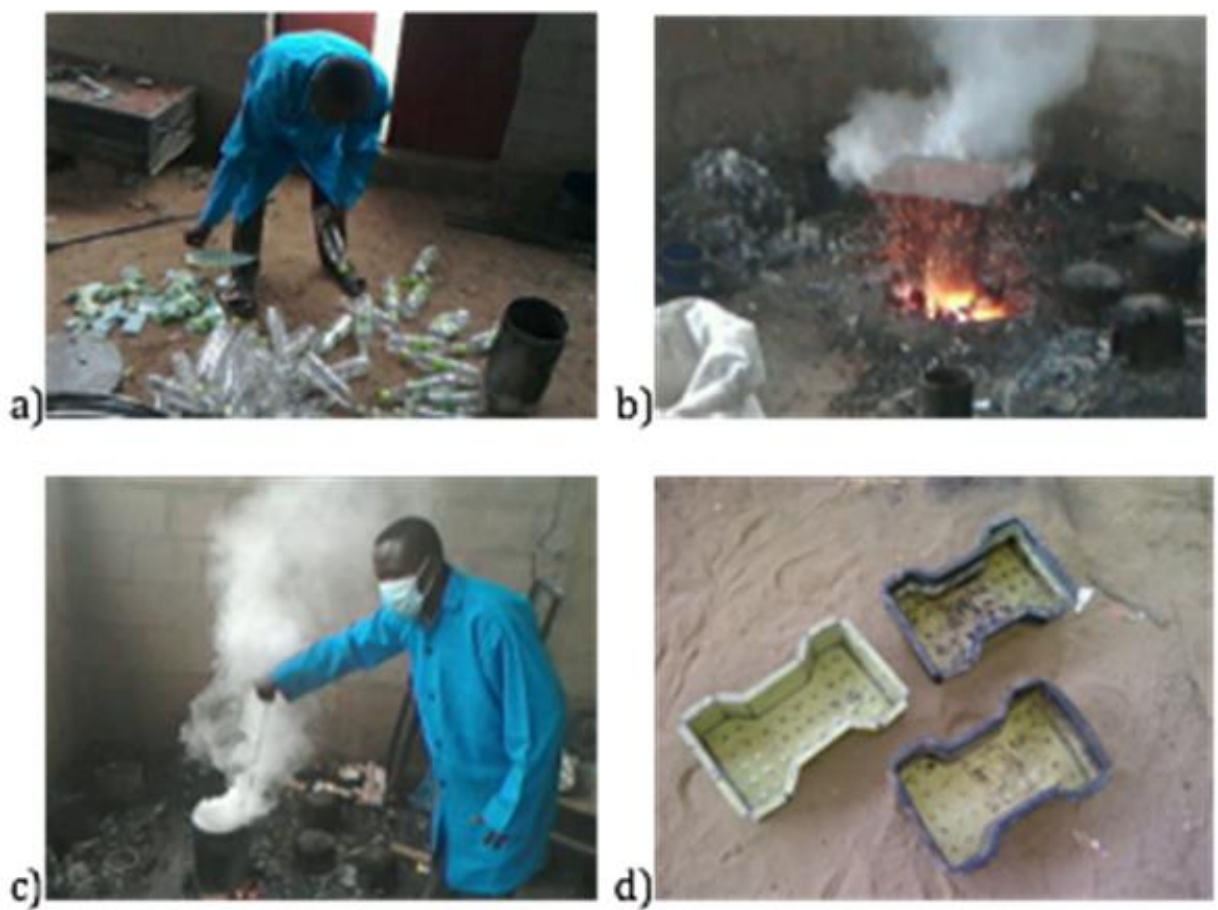

Fig. 2: a) Sorting out impurities from the waste water bottles; b) The melting process; c) Stirring with a skimmer; and d) The metallic moulds. 

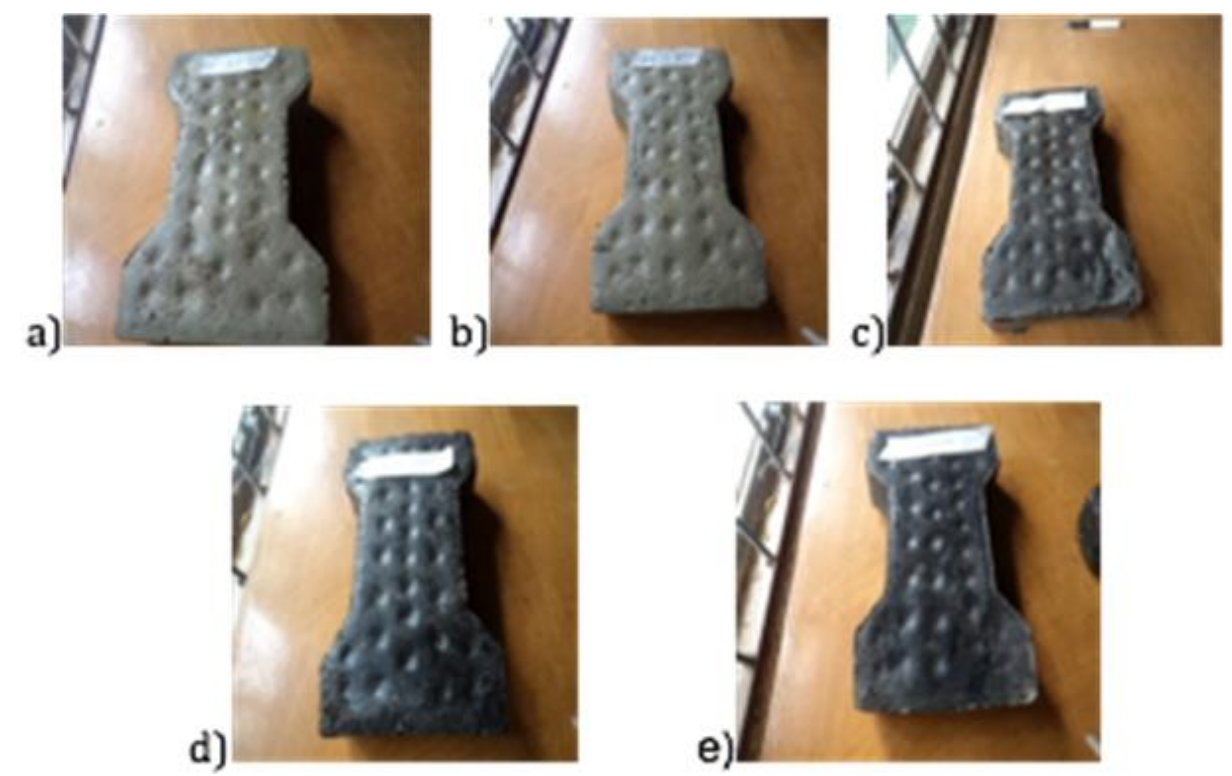

Fig. 3: a) Sample-A waste plastic interlock block at $100 \%$; b) Sample-B interlock block of $75 \%$ waste plastic bottle with $25 \%$ LDPEP; c) Sample-C interlock block of 50\% waste plastic bottle with $50 \%$ LDPEP; d) Sample-D interlock block of $25 \%$ plastic waste with \% LDPEP; and e) Sample-E interlock block 100\% low dense polyethylene plastic waste.

\subsection{Waste Melting and Block Production}

The weights of the different wastes were determined using a calibrated laboratory weighing balance. In other to achieve the required aim, the melting process was carried out using a charcoal-fired furnace at temperature $1200 \mathrm{C}$ to $2000 \mathrm{C}$. The melted wastes were then poured into the mould. The internal surface of the mould was lubricated with spent-engine oil for easy removal of the interlock block afterwards. This was subsequently immersed in water for an hour to help in solidification of the block.

\subsection{Unconfined Compressive Strength}

Unconfined compressive strength (UCS) was determined using a universal compressive test machine in accordance with BS 12390-3:2002 on the block samples.

\subsection{Water Absorption}

Water absorption was determined in accordance with BS 1881-122: 1983. The procedure involves immersion of block samples in water at least $125 \mathrm{~mm}$ deep for 24 hours, with the water surface kept at $25 \pm 5$ $\mathrm{mm}$ above the top of the block. The blocks were then removed, excess surface water dried with a damp absorbent cloth and the sample weighed. The difference between the initial dry weight and the saturated weight gives the water absorption according to the formula:

$$
\left[\frac{\left(w_{s a t}-w_{d r y}\right)}{w_{d r y}}\right] \times 100 \%
$$

where:

$$
\begin{aligned}
& \mathrm{W}_{\text {sat }}=\text { the saturated weight of the specimen }(\mathrm{g}) \\
& \mathrm{W}_{\mathrm{dry}}=\text { the initial dry weight of the specimen }(\mathrm{g})
\end{aligned}
$$



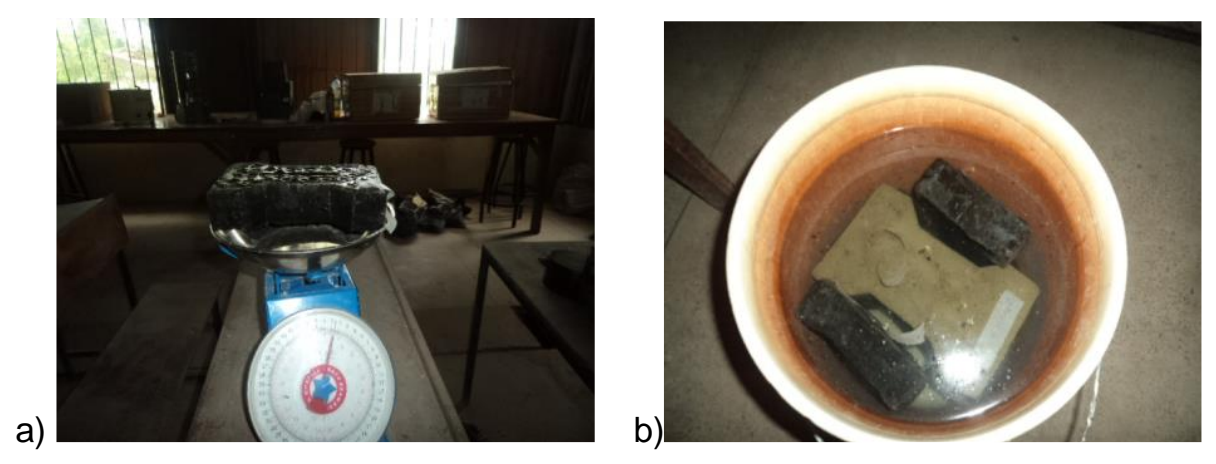

Fig. 4: Methods: a) Weighing of an interlock block sample using a calibrated weighing balance; and b) Test to determine water absorption of a block sample.

\section{Results and Discussions}

\subsection{Results}

The results of the research are presented in the following Tables.

TABLE I: Percentage Mix Compositions of Waste Plastic Bottle and Low Dense Polyethylene Plastic

\begin{tabular}{|c|c|c|}
\hline S/No. & Sample Identity & Sample Composition \\
\hline 1 & A & $100 \%$ Waste Plastic Bottle + 0\% LDPEP \\
\hline 2 & B & $75 \%$ Waste Plastic Bottle + 25\% LDPEP \\
\hline 3 & C & $50 \%$ Waste Plastic Bottle + 50\% LDPEP \\
\hline 4 & D & $25 \%$ Waste Plastic Bottle + 75\% LDPEP \\
\hline 5 & E & $0 \%$ Waste Plastic Bottle + 100\% LDPEP \\
\hline
\end{tabular}

*LDPEP: Low Dense Polyethylene Plastic waste.

TABLE II: Summary of Values Obtain During the Process of Melting Polymer (Waste Plastic Bottle and Waste Low Density Polyethylene)

\begin{tabular}{|c|c|c|c|c|c|c|c|c|}
\hline Sample & $\begin{array}{c}\text { Weight } \\
\text { before } \\
\text { melting } \\
(\mathbf{k g})\end{array}$ & $\begin{array}{c}\text { Duration } \\
\text { after } \\
\text { melting } \\
(\mathbf{m i n s})\end{array}$ & $\begin{array}{c}\text { Duration for } \\
\text { demoulding } \\
(\mathbf{m i n s})\end{array}$ & $\begin{array}{c}\text { Area } \\
\left(\mathbf{m}^{\mathbf{2}}\right)\end{array}$ & $\begin{array}{c}\text { Volume } \\
\left(\mathbf{m}^{\mathbf{3}}\right)\end{array}$ & $\begin{array}{c}\text { Weight } \\
\text { after } \\
\mathbf{m e l t i n g} \\
(\mathbf{k g})\end{array}$ & $\begin{array}{c}\text { Water } \\
\text { Absorption } \\
(\boldsymbol{\%})\end{array}$ & $\begin{array}{c}\text { Compressive } \\
\text { Strength } \\
(\mathbf{M P a})\end{array}$ \\
\hline $\mathrm{A}$ & 4.0 & 45 & 60 & 0.0241 & 0.00121 & 1.1 & 0 & \\
\hline $\mathrm{B}$ & 4.0 & 60 & 60 & 0.0241 & 0.00121 & 1.1 & 0 & 7 \\
\hline $\mathrm{C}$ & 4.0 & 85 & 60 & 0.0241 & 0.00121 & 1.1 & 0 & 10 \\
\hline $\mathrm{D}$ & 4.0 & 95 & 60 & 0.0241 & 0.00121 & 1.2 & 0 & 14 \\
\hline $\mathrm{E}$ & 4.0 & 120 & 60 & 0.0241 & 0.00121 & 1.1 & 0 & 18 \\
\hline
\end{tabular}

TABLE 3: Data on time taken for melting waste plastic bottle and low dense polyethylene plastic on the basis of composition

\begin{tabular}{|c|c|c|c|c|c|}
\hline \multicolumn{2}{|c|}{ Sample Composition and Waste Content (\%) } & 100 & 75 & $\mathbf{5 0}$ & 25 \\
\hline & Waste Plastic Bottle (mins) & 45 & 60 & 85 & 95 \\
\hline $\begin{array}{l}\text { Duration Ior melting } \\
\text { waste plastic bottle (mins) }\end{array}$ & $\begin{array}{l}\text { Waste Low Dense Polyethylene Plastic } \\
\text { (mins) }\end{array}$ & 120 & 95 & 85 & 60 \\
\hline
\end{tabular}




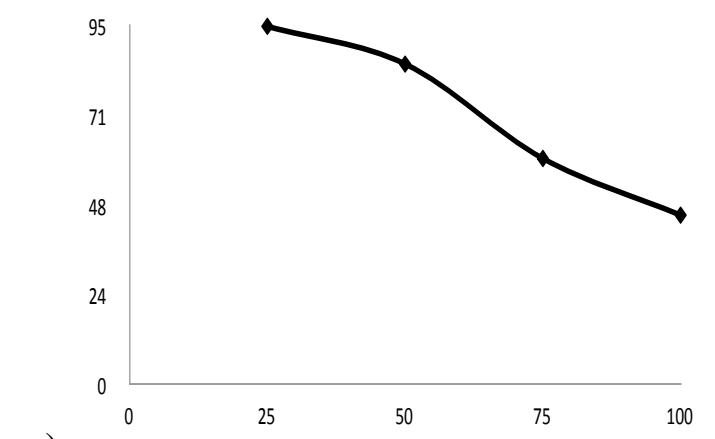

a)

Fig. 5: Data on time taken for melting of a) waste plastic bottle; and b); waste low dense polyethylene plastic with reference to percentage wastes combinations.

TABLE 4: Compressive Strength of Waste Plastic Vs Each \% Combination with Low Dense Polyethylene Waste.

\begin{tabular}{|c|c|c|c|c|c|}
\hline \multicolumn{2}{|c|}{ Sample Composition and Waste Content (\%) } & $\mathbf{1 0 0}$ & $\mathbf{7 5}$ & $\mathbf{5 0}$ & $\mathbf{2 5}$ \\
\hline \multirow{2}{*}{$\begin{array}{c}\text { Compressive Strength } \\
\text { (MPa) }\end{array}$} & $\begin{array}{c}\text { Waste Plastic Bottle (MPa) } \\
\text { Waste Dense Polyethylene } \\
\text { Plastic (MPa) }\end{array}$ & 24 & 18 & 14 & 18 \\
\hline
\end{tabular}

TABLE 5: Comparison of the Compressive Strengths of the Interlock Blocks At Different Percentage

Wastes Compositions.

\begin{tabular}{|c|c|c|c|}
\hline S/No. & $\begin{array}{c}\text { Sample } \\
\text { Identity }\end{array}$ & Sample Composition & Compressive Strength (MPa) \\
\hline $\mathbf{1}$ & A & $100 \%$ Waste Plastic Bottle + 0\% LDPEP & 7 \\
\hline $\mathbf{2}$ & B & $75 \%$ Waste Plastic Bottle + 25\% LDPEP & 10 \\
\hline $\mathbf{3}$ & C & $50 \%$ Waste Plastic Bottle + 50\% LDPEP & 14 \\
\hline $\mathbf{4}$ & D & 25\% Waste Plastic Bottle + 75\% LDPEP & 18 \\
\hline $\mathbf{5}$ & E & $0 \%$ Waste Plastic Bottle + 100\% LDPEP & 24 \\
\hline $\mathbf{6}$ & Control & Concrete (1:2:4) & 17 \\
\hline
\end{tabular}

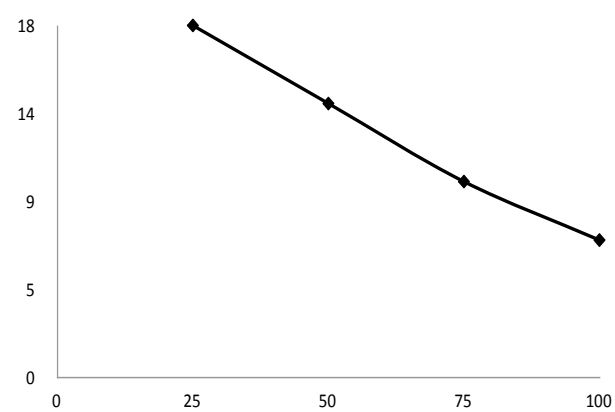

a)

Fig. 6: Data on Compressive strength of a) waste plastic bottle; and b); waste low dense polyethylene plastic with reference to percentage wastes combinations.

\subsection{Discussions}

The results show that the duration required for melting waste polyethylene plastic is longer than that for waste plastic bottle. It was also observed that the compressive strength yielded by blocks with higher waste polyethylene plastic was higher than that with higher waste plastic bottle, while a combination of the two materials can also be suitable for production of interlock blocks. However, it is not advisable to use only plastic bottle waste alone in production of interlock blocks because of the low compressive strength recorded. From comparison of the compressive strength results of recycling polymer waste (polyethylene and plastic bottle waste) as interlock blocks and the conventional concrete interlock paver, it was found that polymer waste gave a higher compressive strength than conventional concrete interlock blocks. Also recycling of polymer waste would 
lead to reduced environmental pollution and make waste polymer a recyclable material.

\section{Conclusions}

Based on result of study, the following conclusions were drawn:

a) The duration for melting polyethylene waste for production of interlock block is longer than that of plastic bottle waste; b) the extent to which higher percentage of plastic bottle waste is added reduces the duration of melting of polymer and also reduces the compressive strength of the interlock block; c) the compressive strength of polyethylene is higher than that of plastic bottle waste; d) the compressive strength of polyethylene is also higher than that of conventional concrete interlock blocks; e) recycling of the two waste plastics creates opportunities for value recovery and would contribute to reducing environmental pollution especially since waste plastic does not decay easily.

Additionally, from the compressive strength results it appears there is advantage in recycling this waste stream into interlock block since the values obtained are not only comparable to that conventional concrete interlocks but also higher in some instances.

\section{References}

[1] Y. Xue, H. Hou, S. Zhu and J. Zha, "Utilization of Municipal Solid Waste Incineration Ash in Stone Mastic Asphalt Mixture: Pavement Performance and Environmental Impact”, Construction and Building Materials, vol. 23, pp. 989996, 2009.

https://doi.org/10.1016/j.conbuildmat.2008.05.009

[2] M. Cyr, J. E. Aubert, B. Husson and P. Clastres, "Recycling Waste in Cement Based Materials: a Studying Methodology" in RILEM Proceedings of the Conference on the Use of Recycled Materials in Building and Structures, Barcelona, Spain, 2004, pp. 306-315.

[3] R. Siddique, "Use of municipal solid waste ash in concrete”, Resources, Conservation and Recycling, vol. 55(2), pp. 83-91, 2010.

https://doi.org/10.1016/j.resconrec.2010.10.003

[4] B. Mohammed and C. R. Cheeseman, "Use of Oil Drill Cuttings as an Alternative Raw Material in Sandcrete Blocks”, Waste and Biomass Valorization, vo. 2(4), pp. 373-380, 2011.

https://doi.org/10.1007/s12649-011-9089-z

[5] A. Valavanidid, N. Iliopoulos, G. Gotsis and K. Fiotakis, "Persistent free radicals, heavy metals and PAHs generated in particulate soot emissions and residual ash from controlled combustion of common type of plastics", Journal of Hazardous Materials, vol. 156, pp. 277-284, 2004.

https://doi.org/10.1016/j.jhazmat.2007.12.019

[6] Z. Wang, H. Richter, J. B. Howard, J. Jordan, J. Carlson and Y. A. Levendis, "Laboratory investigation of the products of the incomplete combustion of waste plastics and techniques for their minimization", American Chemical Society, Ind. Eng. Chem. Res., vol. 43, pp. 2873-2886, 2004.

https://doi.org/10.1021/ie030477u

[7] Anatole A. Klyosov, Wood-Plastic Composites, John Wiley \& Sons, Inc., Hoboken, New Jersey, USA, 2007.

[8] ASTM Standard D 638M-93, 'Test method for tensile properties of plastics”, American Society for Testing and Materials, Philadelphia, Pennsylvania, USA, 2005.

[9] H. Lee, L. Wang and J. F. Shin, "Mutagenicity of particulates from the laboratory combustion of plastics", Mutat. Res., vol. 346, pp. 135-144, 1995.

https://doi.org/10.1016/0165-7992(95)90045-4

[10] I. O. Agbede and J. Manasseh, "Use of cement: Sand admixture in laterite brick production for low cost housing", 
Leonardo Electronic Journal of Practices and Technologies, vol. 12, pp. 163-174, January-June 2008.

[11] S. O. Folagbade, "Characteristics of cement stabilised sandy: Lateritic hollow blocks", Journal of Environmental Design and Management, vol. 1(1\&2), pp. 67-74, 1998.

[12] J. Yang, W. Liu, Z. Lili and B. Xiao, "Preparation of Load-Bearing Materials from Autoclaved Phosphogypsum", Construction and Building Materials, vol. 23, pp. 687-693, 2009.

https://doi.org/10.1016/j.conbuildmat.2008.02.011 